\title{
Retrospective Analysis of Pesticide Poisoning in Rural
}

\section{Area}

\author{
Derya Adibelli ${ }^{1 *}$, Ilknur Özkan ${ }^{1}$, Hasan Ömür Özkan ${ }^{2}$ \\ ${ }^{1}$ Kumluca Health Science Faculty, Akdeniz University, Antalya, Turkey \\ ${ }^{2}$ Kumluca Public Hospital, Antalya, Turkey
}

\begin{abstract}
Acute pesticide poisoning is an important public health problem. This research was done for the purposes of retrospectively examining the relationships between the recorded pesticide poisonings and socio-demographic factors.

This retrospective descriptive study was conducted between December 2017 and February 2018. It was examined that thirty-two cases presented for pesticide poisoning between January 1, 2008 and December 31, 2017 to the Emergency Service of the Kumluca Public Hospital. The hospital records were used to collect the research data. The $\chi^{2}$ test and logistic regression analysis were used, as well as descriptive statistics.

It was found that 12 cases used pesticides to commit suicide, and 9 cases presented to psychiatry polyclinics after a suicide attempt. It was found that pesticide poisoning was mostly in spring. The poisonings occurred most often via the gastrointestinal tract, inhalation, skin respectively. It was found that poisoning in order to attempt suicide in women we re higher, and accidental and professional poisonings in men were higher. In the logistic regression analysis, it was found that the use of pesticides to commit suicide differed according to the gender $(\mathrm{OR}=0.070, \mathrm{p}<0.05)$.

This study revealed the existence of pesticide poisonings, and especially, suicidal attempts due to pesticides in a rural area.
\end{abstract}

Key Words: Pesticide, pesticide poisoning, retrospective, rural

\section{Introduction}

Acute pesticide poisoning is an important professional disease and public health problem in both undeveloped and developing countries (1-3). In many countries, the rate of pesticide poisonings is not known due to the inadequacies and weaknesses in the recording systems $(4,5)$. Moreover, the ease with which pesticides can be obtained can increase the poisoning rate $(1,5)$. Many of the pesticides responsible for poisoning people are neurotoxic agents, such as cholinesterase inhibitors. The soluble lipid forms of the pesticides in the organophosphate group, especially, can lead to long term systemic effects by accumulating in the liver and brain (6). In addition, severe poisoning related to certain organochlorines can lead to status epilepticus (7). Acute exposure to phosphite, which is another type of pesticide, via digestion can affect many organs, and it can also lead to death as a result of cardiac insufficiency. Individuals lose their lives due to exposure, despite intensive care, because there are no special antidotes for these products.

Acetylcholinesterase inhibition is the primary mechanism of toxicity in pesticides.
Acetylcholinesterase can be found in the central nervous system, peripheral nervous system, neuromuscular junction, and erythrocytes, and its central role is to stimulate neurotransmitter activity $(8,9)$. When organophosphates inhibit this enzyme, acetylcholine accumulates at the synapses, causing excessive receptor stimulation $(10,11)$. Cholinergic symptoms can be seen as a result of this type of poisoning (12), and these symptoms can last from a few minutes to a few hours. Life threatening situations can occur in the central nervous, cardiovascular, respiratory, gastrointestinal, and musculoskeletal system via the distribution of cholinergic neurons.

Mental health researchers and clinicians have recently begun to pay attention to the effects of environmental and professional exposures to certain chemicals on the neurochemical activity in the brain and the occurrence of psychiatric disorders. Current research shows that excessive exposure to organophosphates is related to high rates of depression and suicide, especially among agricultural workers (13-16). The use of pesticides for the purpose of committing suicide via digestion is an important problem in many Asian countries, including India, Sri Lanka, and Pakistan. 


\section{$\approx$ AUTUMN $=$ WINTER $\approx$ SPRING $=$ SUMMER}

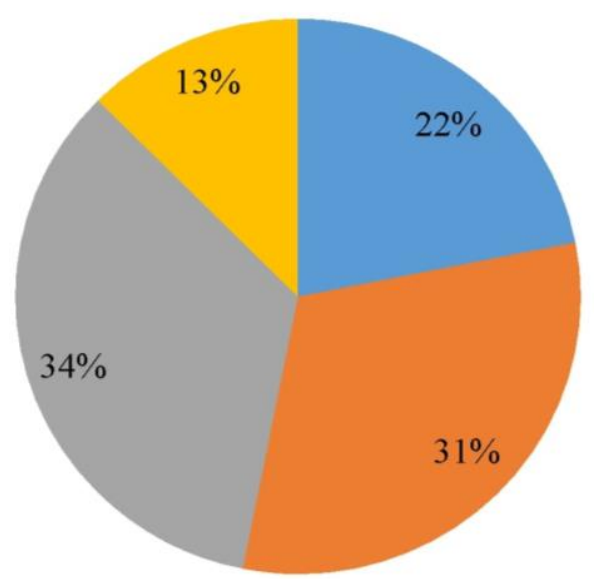

Fig 1. Seasonal distribution of poisoning cases

While the mortality rate related to deliberately trying to poison oneself is $15-30 \%$ in India, this rate is approximately $1-2 \%$ in developed countries $(17,18)$. Worldwide, the suicide attempt rate via the use of pesticides constitutes $14-20 \%$ of all general suicide attempts (19). Nearly one million people lose their lives due to suicides every year, and it is estimated that the deaths caused by chemical products in the pesticide group number approximately $370,000(20)$.

Agriculture is one of the main means of living in rural areas in low and middle income countries; therefore, pesticides are easier to obtain in these areas. Even if pesticides are ingested at low doses, they can show highly toxic effects (21). Exposure to pesticides at acute and chronic levels can lead to many neurodegenerative diseases, such as neurobehavioral disorders, cognitive impairment, peripheral nervous system changes, neuropathy, Alzheimer's disease, and Parkinson's disease, as well as depression and suicide (22-24). Although depression and suicide show different results, and they can be analyzed individually, they are not totally independent from each other, because depression is the most common cause of a suicide attempt (25). Attempted suicide is a complex condition that needs to be researched and examined in many aspects. Although working in an agricultural area has been shown to be a risk factor for suicide in many studies in the literature, other situations, apart from pesticide exposure, must also be assessed. Agricultural workers can encounter many different dangers, such as chemical exposure in work areas, work equipment use, heavy machinery use, and extreme physical activity. All these can put an individual at risk for substance abuse, injuries, and suicide attempts (26). Moreover, agricultural workers can be a more

\section{$\square$ GIS $\square$ INHALATION $\square$ SKIN}

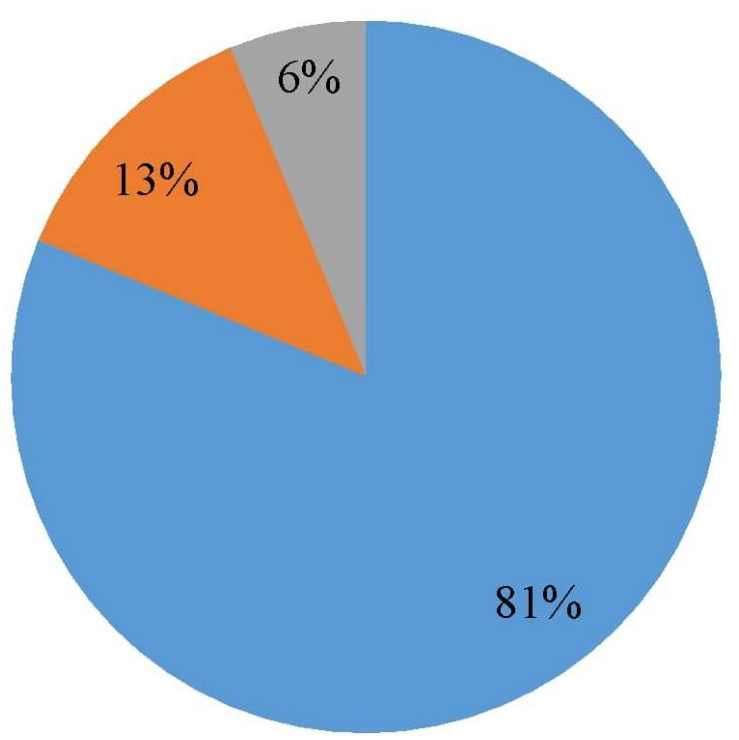

Fig 2. Distribution of cases according to the poisoning route

sensitive group with regard to the suicide risk due to many sociodemographic factors, including a low educational level, low family income level, social isolation, and insufficient personal protective equipment usage (13). In recent years, different strategies have been used in order to decrease suicide attempts with various implementations, such as keeping pesticides in locked cupboards (27). Even if this approach is advantageous, especially for the pesticide industry, an extensive study was done in Sri Lanka showed that it was not very effective (28).

Greenhouse agriculture is generally done in areas with a mild climate, and it is commonly seen in our country (Turkey), which is in the Mediterranean region. According to the United Nations Food and Agriculture Organization (FAO) data, "greenhousing" is done in a 1.2 million hectare area around the world today. The largest greenhousing area in the world includes the Mediterranean basin, and Turkey has bigger greenhousing potential than the other Mediterranean countries. Turkey ranks fourth in the world in greenhousing area. It ranks third among the Mediterranean countries, after Spain and Italy, and it ranks second after Spain in terms of the greenhousing area in which vegetables are grown. When it comes to domestic areas, the region from which the research data was taken is placed first in greenhousing production (29). 


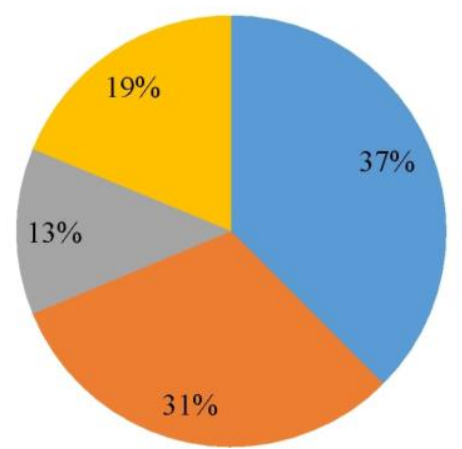

Fig 3. Distribution of cases according to poisoning situation

The epidemiological data is limited in terms of the direct effects of chronic or low dose pesticide exposure, and many epidemiological and sociodemographic factors play roles in the relationship between depression and suicide. However, recent views suggest that pesticide exposure can be a risk factor for depression and suicide. The fact that many of the suicide attempts are coded as poisonings in the country's data set makes the analysis of cases more difficult. Therefore, this research was done for the purposes of retrospectively examining the relationships between the recorded pesticide poisonings and the sociodemographic factors.

\section{Materials and Methods}

Research type: This retrospective descriptive study was conducted between December 2017 and February 2018. Thirty-two cases (14 females, 18 males) who presented for pesticide poisoning between January 1, 2008 and December 31, 2017 to the Emergency Service of the Kumluca Public Hospital were examined in this research.

Data collection: A data record form was prepared by the researchers in line with literature, and the hospital records were used to collect the research data. The form included questions about the age, gender, type of chemical or drug causing the poisoning, whether drugs were used to commit suicide or not, season in which the poisoning occurred, poisoning route, suicide attempt situation, symptoms and findings in the case, and necessity for intensive care. The poising situations were classified as follows: a - suicide, b - accident, c - professional, d - homicide, and e - unknown circumstances. The data was collected from the condition of the patients while they were presenting in those cases in which the records were uncertain. For instance, a case in which an adult took the pesticide deliberately through the gastrointestinal tract was assessed as a suicide attempt, while that of a child that took the pesticide through the gastrointestinal tract was assessed as an accident. Similarly, a pesticide poisoning during implementation was classified as a professional poisoning, while poisoning someone else deliberately was classified as a homicide.

The patient results were classified as follows: arecovery, b-escaping, c-referring, d-refusing treatment, e-death, and f-unknown circumstances. The agents to which the patients were exposed were classified as: a - insecticide or b-other.

Data Analysis: IBM SPSS (version 23.0) statistics package program was used in the assessment of data. The $\chi^{2}$ test and logistic regression analysis were used, as well as descriptive statistics, in the examination of the relationships between the poisoning situation and the exposure agent, age, gender, and poisoning result.

Ethical Principles: Patient consent was not required in this study because only the recorded data was used. Approval was obtained from the Akdeniz University Medical Faculty Clinical Studies Ethics Committee (70904504/19-28), and written permission was provided by the health institution from which the data was obtained.

Limitations: Distinguishing pesticide poisonings is difficult, because poisonings are only coded in one category in hospital record systems. In addition, the agent to which the patient was exposed, the poisoning severity, and the results were not documented systematically, constituting a limitation for this research.

\section{Results}

When the general characteristics of the poisoning cases were examined, it was found that 12 cases used pesticides to commit suicide, and 9 cases presented to psychiatry polyclinics after a suicide attempt. The symptoms and findings were not generally provided, with the exception of a stomachache in one case, and severe sweating and a slight increase in the creatinine values in another case. The follow-ups included intensive care after a gastric lavage and the implementation of activated charcoal in the suicide attempts and gastrointestinal tract poisonings. The patients were followed-up in the emergency service in those poisonings that were due to inhalation and skin exposure (Table 1). 
Table 1. General characteristics of the pesticide poisoning cases

\begin{tabular}{|c|c|c|c|c|c|c|c|c|}
\hline Age* & Gender* & Exposure agent & $\begin{array}{c}\text { Route of } \\
\text { poisoning** }\end{array}$ & $\begin{array}{l}\text { Suicide } \\
\text { situation }\end{array}$ & $\begin{array}{l}\text { Poisoning } \\
\text { season }\end{array}$ & $\begin{array}{l}\text { Symptoms and } \\
\text { findings }\end{array}$ & $\begin{array}{l}\text { Psychiatric } \\
\text { polyclinic } \\
\text { application }\end{array}$ & Necessity for intensive care \\
\hline 30 & Female & Insecticide & GIS & Yes & Winter & Absent & Yes & $\begin{array}{l}\text { Gastric lavage, activated charcoal, } \\
\text { follow-up in intensive care }\end{array}$ \\
\hline 44 & Male & Insecticide & GIS & Yes & Winter & Absent & No & $\begin{array}{l}\text { Gastric lavage, activated charcoal, } \\
\text { follow-up in intensive care }\end{array}$ \\
\hline 1 & Female & Other pesticide & GIS & No & Spring & Absent & No & Follow-up in emergency service \\
\hline 15 & Female & Insecticide & GIS & Yes & Spring & Absent & Yes & $\begin{array}{l}\text { Gastric lavage, activated charcoal, } \\
\text { follow-up in intensive care }\end{array}$ \\
\hline 5 & Male & Other pesticide & GIS & No & Summer & Absent & No & Clinical inpatient and follow-up \\
\hline 65 & Male & Insecticide & GIS & No & Autumn & Absent & No & Follow-up in emergency service \\
\hline 2 & Male & Insecticide & GIS & No & Summer & Absent & No & $\begin{array}{c}\text { Gastric lavage, activated charcoal, } \\
\text { follow-up in intensive care }\end{array}$ \\
\hline 64 & Male & Insecticide & GIS & No & Autumn & Absent & No & Follow-up in intensive care \\
\hline 3 & Male & Insecticide & GIS & No & Autumn & Absent & No & Clinical inpatient and follow-up \\
\hline 22 & Female & Insecticide & GIS & Yes & Spring & Absent & No & $\begin{array}{l}\text { Gastric lavage, activated charcoal, } \\
\text { follow-up in intensive care }\end{array}$ \\
\hline 33 & Male & Insecticide & GIS & No & Spring & Absent & No & Follow-up in emergency service \\
\hline 51 & Male & Insecticide & Inhalation & No & Spring & Absent & No & Follow-up in emergency service \\
\hline 46 & Female & Insecticide & GIS & Yes & Spring & Absent & Yes & Follow-up in intensive care \\
\hline 43 & Female & Insecticide & GIS & Yes & Autumn & Absent & Yes & $\begin{array}{c}\text { Gastric lavage, activated charcoal, } \\
\text { follow-up in intensive care }\end{array}$ \\
\hline 22 & Male & Insecticide & GIS & No & Summer & Absent & No & $\begin{array}{l}\text { Gastric lavage, activated charcoal, } \\
\text { follow-up in intensive care }\end{array}$ \\
\hline 2 & Male & Insecticide & GIS & No & Spring & Absent & No & Clinical inpatient and follow-up \\
\hline 1 & Male & Insecticide & GIS & No & Winter & Absent & No & Clinical inpatient and follow-up \\
\hline 2 & Female & Insecticide & Skin & No & Spring & Absent & No & Follow-up in emergency service \\
\hline 26 & Male & Insecticide & Inhalation & No & Autumn & Absent & No & Follow-up in intensive care \\
\hline 52 & Male & Insecticide & GIS & No & Autumn & Stomachache & No & Gastric lavage, follow-up in \\
\hline
\end{tabular}

East J Med Volume:24, Number:3, July-September/2019 


\begin{tabular}{|c|c|c|c|c|c|c|c|c|}
\hline & & & & & & & & emergency service \\
\hline 49 & Female & Insecticide & GIS & Yes & Winter & Absent & Yes & $\begin{array}{l}\text { Gastric lavage, activated charcoal, } \\
\text { follow-up in intensive care }\end{array}$ \\
\hline 30 & Female & Insecticide & GIS & Yes & Winter & Absent & Yes & $\begin{array}{c}\text { Gastric lavage, follow-up in } \\
\text { intensive care }\end{array}$ \\
\hline 17 & Female & Other pesticide & GIS & Yes & Spring & Absent & Yes & Follow-up in intensive care \\
\hline 38 & Female & Insecticide & GIS & Yes & Winter & Absent & No & $\begin{array}{l}\text { Gastric lavage, activated charcoal, } \\
\text { follow-up in intensive care }\end{array}$ \\
\hline 47 & Female & Insecticide & GIS & No & Winter & Absent & No & $\begin{array}{l}\text { Gastric lavage, activated charcoal, } \\
\text { follow-up in intensive care }\end{array}$ \\
\hline 19 & Male & Insecticide & GIS & Yes & Autumn & Absent & Yes & $\begin{array}{c}\text { Gastric lavage, activated charcoal, } \\
\text { follow-up in intensive care }\end{array}$ \\
\hline 31 & Female & Insecticide & GIS & No & Winter & Absent & No & $\begin{array}{l}\text { Gastric lavage, activated charcoal, } \\
\text { follow-up in intensive care }\end{array}$ \\
\hline 37 & Male & Insecticide & GIS & Yes & Winter & Absent & Yes & $\begin{array}{l}\text { Gastric lavage, activated charcoal, } \\
\text { follow-up in intensive care }\end{array}$ \\
\hline 17 & Female & Insecticide & Inhalation & No & Spring & Absent & No & Follow-up in emergency service \\
\hline 45 & Male & Insecticide & GIS & No & Winter & Absent & No & Refusing treatment \\
\hline 27 & Male & Insecticide & Inhalation & No & Summer & Absent & No & Follow up in emergency service \\
\hline 72 & Male & Insecticide & GIS & No & Summer & $\begin{array}{l}\text { Severe sweating, } \\
\text { slight increase in } \\
\text { creatinine }\end{array}$ & No & $\begin{array}{l}\text { Gastric lavage, activated charcoal, } \\
\text { follow-up in intensive care }\end{array}$ \\
\hline
\end{tabular}

**GIS: Gastrointestinal system

East J Med Volume:24, Number:3, July-September/2019 
Table 2. Relationships between the gender and the poisoning data

\begin{tabular}{|c|c|c|c|}
\hline & \multicolumn{2}{|c|}{$\begin{array}{c}\text { Gender } \\
\text { (Number, \%) }\end{array}$} & \multirow[t]{2}{*}{ Test and significance } \\
\hline & Female & Male & \\
\hline \multicolumn{4}{|l|}{ Exposure agent } \\
\hline Insecticide & $12(85.7 \%)$ & $17(94.4 \%)$ & $\chi^{2}=0.706$ \\
\hline Other & $2(14.3 \%)$ & $1(5.6 \%)$ & $\mathrm{p}=0.568$ \\
\hline \multicolumn{4}{|l|}{ Poisoning route } \\
\hline GIS* & $12(85.7 \%)$ & $14(77.8 \%)$ & $\chi^{2}=0.664$ \\
\hline Inhalation & $1(7.1 \%)$ & $3(16.7 \%)$ & $\mathrm{p}=0.717$ \\
\hline Skin & $1(7.1 \%)$ & $1(5.6 \%)$ & \\
\hline \multicolumn{4}{|l|}{ Poisoning situation } \\
\hline Suicide & $9(64.3 \%)$ & $3(16.7 \%)$ & $\chi^{2}=7.890$ \\
\hline Accident & $2(14.3 \%)$ & $8(44.4 \%)$ & $\mathrm{p}=0.048$ \\
\hline Occupational & $1(7.1 \%)$ & $3(16.7 \%)$ & \\
\hline Unknown & $2(14.3 \%)$ & $4(22.2 \%)$ & \\
\hline \multicolumn{4}{|l|}{ Poisoning season } \\
\hline Autumn & $1(7.1 \%)$ & $6(33.3 \%)$ & $\chi^{2}=10.231$ \\
\hline Winter & $6(42.9 \%)$ & $4(22.2 \%)$ & $\mathrm{p}=0.017$ \\
\hline Spring & $7(50.0 \%)$ & $3(16.7 \%)$ & \\
\hline Summer & $0(0.0 \%)$ & $5(27.8 \%)$ & \\
\hline \multicolumn{4}{|l|}{ Patient results } \\
\hline Recovery & $13(92.9 \%)$ & $11(61.1 \%)$ & $\chi^{2}=4.305$ \\
\hline Referring & $1(7.1 \%)$ & $6(33.3 \%)$ & $\mathrm{p}=0.116$ \\
\hline Refusing treatment & $0(0.0 \%)$ & $1(5.6 \%)$ & \\
\hline
\end{tabular}

\section{*GIS: Gastrointestinal system}

It was found that $34 \%$ of the cases presented to the emergency service in the spring, with $31 \%$ in winter, $22 \%$ in autumn, and $13 \%$ in summer (Figure 1). The poisonings occurred most often via the gastrointestinal tract $(81 \%)$ (inhalation $13 \%$, skin 6\%) (Figure 2).

When the case distribution was examined according to the poisoning situation, the highest number of poisonings was related to suicides $(37 \%)$. In addition, $31 \%$ of the patients were poisoned accidently, $13 \%$ of them were poisoned during occupational application, and in 19\% of them, the poisoning situation was unknown (Figure 3).

When the relationships between the poisoning data and the genders of the cases were examined, it was found that poisoning in order to attempt suicide in women were higher, and accidental and professional poisonings in men were higher. In addition to this, poisoning was seen more often in women in the spring and winter, while it was seen more often in the autumn and summer in men ( $p$ $<0.05)$. No statistical significances were found among the exposure agents, poisoning routes, poisoning situations, and patient results according to the gender $(p>0.05)$ (Table 2).

In the multivariable analysis was done using logistic regression, it was found that the use of pesticides to commit suicide differed according to the gender [Odds Ratio (OR) $=0.070, \mathrm{p}=0.009]$. However no relationship was confirmed between the pesticide exposure type and the use of pesticides to commit suicide $(\mathrm{OR}=0.214, \mathrm{p}=$ 0.311) (Table 3).

\section{Discussion}

The WHO describes pesticide poisoning as the most important suicide instrument in the world (30). The unprotected and unconscious use of pesticides threatens human life, and it can lead to environmental problems. Pesticide poisoning can occur as a result of agricultural usage, accidental exposure, and purposeful use to commit suicide and murder (31). Although most pesticides are used in developed countries and countries with higher economic power, most pesticide poisonings occur in undeveloped and developing countries. 
Table 3. Logistic regression analysis of the use of pesticides to commit suicide, gender of the cases, and pesticide exposure types

\begin{tabular}{lcc}
\hline Characteristics & $\begin{array}{c}\text { OR }(\text { Odds Ratio }) \\
(95 \% \mathrm{CI})\end{array}$ & \\
\cline { 2 - 3 } & Used for committing suicide \\
\cline { 2 - 3 } Gender (Female-Male) & $0.070(0.010-0.512)$ & 0.009 \\
Exposure agent (Insecticide-Other) & $0.214(0.011-4.223)$ & 0.311 \\
\hline${ }_{\mathrm{p}}<0.05$ &
\end{tabular}

${ }^{* p}<0.05$

This situation generally stems from a lack of information about safe standards, not using personal protective equipment, not reading the pesticide labels, and not having enough information about the harm that pesticides can do (32).

This research determined that the gender and average age of the cases were similar. In addition, the vital signs and findings (except for a stomach ache in one case, and severe sweating and a rise in the creatinine in another case) after the poisonings were not found. No deaths due to poisoning were seen in any of the cases, and it was confirmed that they were followed-up with emergency service interventions and intensive care. Several symptoms, such as depression, joylessness, fatigue, lack of energy, stress, and anxiety, were seen in one study in people experiencing pesticide poisoning, and a decrease in energy and activity was confirmed in the poisoned group (33). In addition, findings regarding regression in the neurobehavioral functions, such as the coordination, reaction time, continuous attention, and memory weakness, in the poisoning cases were confirmed in several studies $(34,35)$. The symptom durations and findings after poisoning were related to several factors, including the quantity and density of the exposure agent and the time that passed until presenting to the health institution, and it is believed that the differences among the study results stem from this situation.

It was also found that the pediatric cases tended experienced pesticide poisoning accidently. In support of our study findings, many of the previous studies also determined that children experienced pesticide exposure accidently (36-38). Children are curious by nature, and they like discovering new things, which means that they have a tendency to get hurt. A poisoning can occur when the negligence of the parents is added to a child's sense of wonder. For this reason, pesticides and chemicals must be kept away and stored in locked cupboards. It is very important that measures be taken to keep these substances where children cannot reach them.
The results of this research showed that the poisonings occurred more often in the spring and winter months. In the study, which differed from our findings, it was determined that the pesticide poisoning cases occurred most often in the summer and winter months (39). It was reported that they occurred most often in the spring and summer, and that the deaths due to pesticide poisoning reached the highest level in June (40). In addition, it was reported that poisoning occurred most often during the summer months (41). When this difference among the study results is considered in terms of the pesticide usage time, it can be explained by the pesticide use during different times of the year and in different geographical regions. However, when the poisoning situation is assessed, it is believed that their use to commit suicide is not affected by the season, and that this can occur at any time of the year. The fact that suicidal poisonings contribute toward the biggest share of the cases in all of the studies also supports this view.

This research confirmed that the poisonings occurred most often through the gastrointestinal tract. Previous studies also showed that most of the pesticide poisoning cases occurred through the gastrointestinal tract, with cutaneous exposure being secondary $(38,39,42)$. While exposure through the gastrointestinal system can occur accidentally, and this route can be used to commit suicide, it is believed that exposure through the skin and inhalation tends to occur accidentally or during professional implementation.

Based on the study results, the agent causing poisoning was generally an insecticide. As in this study, previous research conducted in many developing countries has determined that insecticides are the main pesticide agent causing poisoning $(17,31,42,43)$. One study conducted in Brazil confirmed that insecticides were responsible for $75 \%$ of the poisonings that occurred between 1992 and 2002 (44). Similarly, in a study, it was found that herbicides and fungicides were the main pesticides that were responsible for poisoning, in addition to insecticides (33). 
This research showed that the poisonings occurred most often with an intention to commit suicide. Following this, they occurred accidentally and through professional implementation. One study reported that the high suicide rates were seen in agricultural workers were related to acute and chronic pesticide exposure and affective disorders (45). Additionally, it was shown that exposure to pesticides increased psychiatric disorders and suicidal behaviors $(14,34,46,47)$. A study conducted in Brazil reported that the mortality rate due to suicides in agricultural workers between 20 and 39 years old who used pesticides frequently (professionally) was significantly high when compared to the general population (13). However, one large scale cohort study showed that there was no relationship between pesticide exposure and suicide attempts (48). Like our study findings, it was found that the number of suicidal poisonings was higher than that of accidental poisonings (42). Moreover, another study in Costa Rica reported that professional poisonings were the third most frequently seen poisoning type, after poisonings to commit suicide and accidentally (49). It has also been reported in other studies that $60-80 \%$ of pesticide poisonings were the result of a suicide attempt $(31,38,40,50)$. Other studies in the literature support our finding that accidental poisoning is the second most common type, following suicidal poisoning $(51,52)$.

It was found that the suicidal poisoning rate was higher in women, while accidental poisonings and poisonings during professional use were higher in men. The first study about the relationship between pesticides and suicide attempts was done in the 1990s. Following the first decade, several studies about pesticide exposure leading to many health problems as well as increasing suicide attempts and their relationships with agricultural workers were published. Some of these studies reported that the frequency of depression was higher in male agricultural workers than in the men in all other fields. Results also show that the suicide risk was higher (14). Studies supporting our findings shown that the rates of self-poisoning with the use of pesticides were high, especially young women $(53,54)$. Men tend to experience pesticide poisoning accidentally and professional poisoning more often because, generally, men implement chemical pesticides while working in greenhouses (42). One study found that pesticide poisoning occurred among 18-35 year-olds more often, with $64.6 \%$ of the poisonings being suicidal, $34.4 \%$ of them occurring accidentally, and $1 \%$ of them occurring for an unknown reason (38). A study was done in China reported that one of the most common suicide methods was pesticide poisoning in women and men, and that the suicide risk was high for both genders over 45 years of age (55).

\section{Conclusion}

This study is important, because it was the first study in the region in which the research data was examined. It revealed the existence of pesticide poisonings, and especially, suicidal attempts due to pesticides in a rural area. However, the data about the causative agents, poisoning situations, and results could not be documented sufficiently due to insufficient hospital records and a lack of systematic records. Moreover, the hospital record systems do not reflect the care burden for pesticide poisonings directly, and the hospital does not provide facilities for public health initiatives toward poisoning interventions. In this sense, reliable data is needed to create effective initiatives toward decreasing pesticide poisonings as a primary policy in terms of public health. The implementation of systematic data record systems will be effective for revealing the real dimension of pesticide poisonings, and planning initiatives will directly decrease the care burden. Cases, such as professional poisoning, that are not reported to the hospital and deemed to be not serious must be confirmed with personal statements or social research, and farmers must be educated about the use of personal protective equipment. Educational and consciousness-raising studies must be conducted with farmers regarding the storage of these chemicals to prevent pesticide poisoning at home, especially in children.

\section{References}

1. Crowdhary S, Bhattacharyya R, Banerjee D. Acute organophosphorus poisoning. Clin Chim Acta 2014; 431: 66-76.

2. Mathai A, Bhanu MS. Acute aluminium phosphide poisoning: can we predict mortality? Indian J Anaesth 2010; 54: 302-307.

3. Kesavachandran $\mathrm{CN}$, Fareed M, Pathak MK, Bihari V, Mathur N, Srivastava AK. Adverse health effects of pesticides in agrarian populations of developing countries. Rev Environ Contam Toxicol. 2009; 200: 33-52.

4. Litchfield MH. Estimates of acute pesticide poisoning in agricultural workers in less developed countries. Toxicol Rev 2005; 24: 271 278.

5. Lekei E, Ngovi AV, London L. Hospital-based surveillance for acute pesticide poisoning caused 
by neurotoxic and other pesticides in Tanzania. Neurotoxicology 2014; 45: 318-326.

6. Moses V, Peter JV. Acute intentional toxicity: endosulfan and other organochlorines. Clin Toxicol (Phila) 2010; 48: 539-544.

7. Roberts DM, Dissanayake W, Rezvi Sheriff MH, Eddleston M. Refractory status epilepticus following self-poisoning with the organochlorine pesticide endosulfan. J Clin Neurosci 2004; 11: 760-762.

8. Heller M, Hanahan DJ. Human erythrocyte membrane bound enzyme acetylcholinesterase. Biochim Biophys Acta 1972; 255: 251-272.

9. Dvir H, Silman I, Harel M, Rosenberry TL, Sussman JL. Acetylcholinesterase: from 3D structure to function. Chem Biol Interact 2010; 187: 10-22.

10. Hobbiger F. The inhibition of acetylcholinesterase by organophosphorus compounds \& its reversal [Abridged]. Proc R Soc Med 1961; 54: 403-405.

11. Kwong TC. Organophosphate pesticides: biochemistry and clinical toxicology. Ther Drug Monit 2002; 24: 144-149.

12. Singh S, Sharma N. Neurological syndromes following organophosphate poisoning. Neurol India 2000; 48: 308-313.

13. Meyer A, Koifman S, Koifman RJ, Moreira JC, de Rezende Chrisman J, Abreu-Villaca Y. Mood disorders hospitalizations, suicide attempts, and suicide mortality among agricultural workers and residents in an area with intensive use of pesticides in Brazil. J Toxicol Environ Health 2010; 73: 866-877.

14. Freire C, Koiffman S. Pesticides, depression and suicide: a systematic review of the epidemiological evidence. Int J Hyg Environ Health 2013; 216: 445-460.

15. Stallones L, Beseler CL. Assessing the connection between organophosphate pesticide poisoning and mental health: a comparison of neuropsychological symptoms from clinical observations, animal models and epidemiological studies. Cortex 2016; 74: 405-416.

16. Mew EJ, Padmanathan P, Konradsen F, et al. The global burden of fatal self-poisoning with pesticides 2006-2015: systematic review. J Affect Disord 2017; 219: 93-104.

17. Gunnell D, Eddleston M, Phillips MR, Konradsen F. The global distribution of fatal pesticide selfpoisoning: systematic review. BMC Public Health 2007; 7: 357.

18. Somasundaram KV, Patil A, Shukla SK. Epidemiological profile of OP poisoning cases treated at Pravara Hospital, Loni, India. Indian J Soc Prev Med 2009; 40: 185-188.

19. Gunnell D, Knipe D, Chang SS, et al. Prevention of suicide with regulations aimed at restricting access to highly hazardous pesticides: a systematic review of the international evidence. Lancet Glob Health 2017; 5: 1026-1037.
20. Poisoning prevention and management. https://www.who.int/ipcs/poisons/en/ (accessed April 13, 2018).

21. Miller M, Azrael D, Hemenway D. The epidemiology of case fatality rates for suicide in the northeast. Ann Emerg Med 2004; 43: 723-730.

22. Brown TP, Rumsby PC, Capleton AC, Rushton L, Levy LS. Pesticides and Parkinson's disease - is there a link? Environ Health Perspect 2006; 114: 156-164.

23. Rohlman DS, Lasarev M, Anger WK., Scherer J, Stupfel J, McCauley L. Neurobehavioral performance of adult and adolescent agricultural workers. Neurotoxicology 2007; 28: 374-380.

24. Moretto A, Colosio C. Biochemical and toxicological evidence of neurological effects of pesticides: the example of Parkinson's disease. Neurotoxicology 2011; 32: 383-391.

25. London L. Neurobehavioral methods, effects, and prevention: workers' human rights are why the field matters for developing countries. Neurotoxicology 2009; 30: 1135-1143.

26. Beseler CL, Stallones L. Safety knowledge, safety behaviors depression and injuries in Colorado farm residents. Am J Ind Med 2010; 53: 47-54.

27. World Health Organization. (2016). Safer access to pesticides for suicide prevention. Experiences from community interventions. Geneva: World Health Organization.

28. Pearson M, Metcalfe C, Jayamanne S, et al. Effectiveness of household lockable pesticide storage to reduce pesticide self-poisoning in rural Asia: a community-based, cluster-randomised controlled trial. Lancet 2017; 390: 1863-1872.

29. TR63 Bölgesi Seracılık (Örtü altı bitki yetiştiriciliği) Sektör Raporu”, 2015. http://www.dogaka.gov.tr/Icerik/Dosya/www.d ogaka.gov.tr_622_LK5L43WG_Seracilik-ortualtiBitki-Yetistiriciligi-Sektor-Raporu-2015.pdf (accessed March 12, 2018). (in Turkish)

30. Bertolote JM, Fleischmann A, Eddleston M, Gunnell D. Deaths from pesticide poisoning: a global response. Br J Psychiatry 2006; 189: 201 203.

31. Sungur M, Güven M. Intensive care management of organophosphate insecticide poisoning. Crit Care 2001; 5: 211-215.

32. Cantor KP, Blair A, Everett G, et al. Pesticides and other agricultural risk factors for nonHodgkin's lymphoma among men in Iowa and Minnesota. Cancer Res 1992; 52: 2447-2455.

33. Zhang $\mathrm{X}$, Wu M, Yao H, et al. Pesticide poisoning and neurobehavioral function among farm workers in Jiangsu, People's Republic of China. Cortex 2016; 74: 394-406.

34. Mackenzie Ross SJ, Brewin CR, Curran HV, Furlong CE, Abraham-Smith KM, Harrison V. Neuropsychological and psychiatric functioning in sheep farmers exposed to low levels of organophosphate pesticides, Neurotoxicol Teratol 2010; 32: 452-459. 
35. Rohlman DS, Anger KW, Lein PJ. Correlating neurobehavioral performance with biomarkers of organophosphorus pesticide exposure. Neurotoxicology 2011; 32: 268-276.

36. Chhetri UD, Ansari I, Shrestha S. Patterns of pediatric poisoning and accident in Patan Hospital. Kathmandu Univ Med J 2012; 10: 39 43.

37. Balme KH, Roberts JC, Glasstone M, Curling I, Mann MD. The changing trends of childhood poisoning at a tertiary children's hospital in South Africa. S Afr Med J 2012; 102: 142-146.

38. Peshin SS, Srivastava A, Halder N, Gupta YK. Pesticide poisoning trend analysis of 13 years: a retrospective study based on telephone calls at the National Poisons Information Centre, All India Institute of Medical Sciences, New Delhi. J Forensic Leg Med 2014; 22: 57-61.

39. Meral C, Tuncer İ, Topal C, Ayakta H, Durmuș A, Aksoy H. Organik fosfor intoksikasyonları ile ilgili retrospektif araştırma. Van Tıp Dergisi 2000; 7: 163-168.

40. Idiz N, Karakus A, Dalgıç M. The forensic deaths caused by pesticide poisoning between the years 2006 and 2009 in Izmir, Turkey. J Forensic Sci 2012; 57: 1014-1016.

41. Kahraman N, Yanturalı S, Kalkan S, Oray N, Hocaoğlu N, Turhan A. Evaluating the relationship between serum acetylcolinesterase levels and clinical course and mortality of patients presented with organophosphate and carbamate poisonings. Turk J Emerg Med 2008; 8: 121-126.

42. Kır Z, Öztürk G, Gürler M, et al. Pesticide poisoning cases in Ankara and nearby cities in Turkey: an 11-year retrospective analysis. J Forensic Leg Med 2013; 20: 274-277.

43. Vougiouklakis T, Boumba VA, Mitselou A, Peschos D, Gerontopoulos K. Trends in suicide mortality in the deprived region of Epirus (NorthWestern Greece) during the period 1998-2002. Med Sci Law 2006; 45: 39-46.

44. Recena MC, Pires DX, Caldas ED. Acute poisoning with pesticides in the state of Mato Grosso do Sul, Brazil. Sci Total Environ 2006; 357: 88-95.
45. London L, Flisher AJ, Wesseling C, Mergler D, Kromhout M. Suicide and exposure to organophosphate insecticides: cause or effect? Am J Ind Med 2005; 47: 308-321.

46. Wesseling C, van Wendel de Joode B, Keifer M, London L, Mergler D, Stallones L. Symptoms of psychological distress and suicidal ideation among banana workers with a history of poisoning by organophosphate or n-methyl carbamate pesticides. Occup Environ Med 2010; 67: 778784.

47. Macfarlane E, Simpson P, Benke G, Sim MR. Suicide in Australian pesticide-exposed workers. Occup Med (Lond) 2011; 61: 259-264.

48. Beard JD, Umbach DM, Hoppin JA, et al. Suicide and pesticide use among pesticide applicators and their spouses in the Agricultural Health Study. Environ Health Perspect 2011; 119: 1610-1615.

49. Leveridge YR. Pesticide poisoning in Costa Rica during 1996. Vet Hum Toxicol 1998; 40: 42-44.

50. Yürümez Y, Durukan P, Yavuz Y, et al. Acute organophosphate poisoning in university hospital emergency room patients. Intern Med 2007; 46: 965-969.

51. Gargi J, Rai H, Chanana A, Rai G, Sharma G, Bagga IJ. Current trend of poisoning-a hospital profile. J Indian Med Assoc 2006; 104: 72-73.

52. Bose A, Sandal Sejbaek C, Suganthy V, et al. Selfharm and self-poisoning in southern India: choice of poisoning agents and treatment. Trop Med Int Health 2009; 14: 761-765.

53. Aaron R, Joseph A, Abraham S, et al. Suicide in young people in rural people in rural southern India. Lancet 2004; 363: 1117-1118.

54. Prasad J, Abraham VJ, Minz S, et al. Rates and factors associated with suicide in Kaniyambadi Block, Tamil Nadu, South India 2000-02. Int J Soc Psychiatry 2006; 52: 65-71.

55. Page A, Liu S, Gunnell D, et al. Suicide by pesticide poisoning remains a priority for suicide prevention in China: analysis of national mortality trends 2006-2013. J Affect Disord 2017; 208: 418423. 